\title{
TANATOLOGIA: FENÔMENOS CADAVÉRICOS ABIÓTICOS E TRANSFORMATIVOS
}

\section{ARTIGO DE REVISÃO}

BESSA, Vicente Alberto Lima ${ }^{1}$

BESSA, Vicente Alberto Lima. Tanatologia: fenômenos cadavéricos abióticos e transformativos. Revista Científica Multidisciplinar Núcleo do Conhecimento. Ano 05, Ed. 01, Vol. 05, pp. 64-74. Janeiro de 2020. ISSN: 2448-0959, Link de acesso: https://www.nucleodoconhecimento.com.br/saude/tanatologia

\section{RESUMO}

A morte é um mistério para a sociedade e é carregada de conceitos filosóficos, religiosos, mas também há uma base científica: a tanatologia. As mudanças no corpo ocorrem logo após a morte e evoluem ao longo de uma linha do tempo e seu estudo é necessário para gerar fatos que podem ser fundamentais para elucidar um crime. $\mathrm{O}$ objetivo deste estudo foi descrever os fenômenos da morte a partir dos conhecimentos oriundos da tanatologia. Para tanto, foi realizado um estudo de revisão descritiva cujas bases de dados foram: Scielo, RECAAP, PubMed e Web of Science. Inferiu-se que

${ }^{1}$ Doutorado em Treinamento Desportivo (AWU - USA); Mestrado em Ciências da Motricidade Humana (UCB - RJ); Especialização em Treinamento Desportivo e Personal Trainner (UCB - RJ); Especialização em Ginástica Médica (UCB - RJ); Especialização em Tópicos Avançados pela Escola de Medicina da Universidade de Maryland (Baltimore - USA); Especialização em Fisioterapia Dermato-funcional (Unyleya - SP); Especialização em Língua Portuguesa (Simonsen - RJ); Graduado em Fisioterapia (UCB - RJ); Tecnólogo em Estética e Cosmética (Celso Lisboa - RJ); Bacharel e Licenciado em Educação Física (UERJ - RJ); Licenciado em Letras (Simonsen - RJ); Licenciado em Pedagogia (Simonsen - RJ). 
para estabelecer um diagnóstico o perito deverá analisar adequadamente os fenômenos cadavéricos.

Palavras-chave: tanatologia, thanatology, tanatognose.

\section{INTRODUÇÃO}

A morte é a única certeza que o ser humano possui, pois todos sabem que um dia o organismo humano deixará completamente de funcionar. A morte é polêmica e carregada de mistérios, crenças, é tão amedrontadora quanto excitante. A teoria da "decisão final" preocupa-se com as relações entre o corpo e a alma no momento exato em que se detecta fisicamente a ocorrência da morte, logo é quando a alma é separada do corpo que o homem assume o seu destino eterno, salvação ou perdição (OLIVEIRA, 2015).

Todavia, biologicamente, a morte é a cessação das atividades vitais de um organismo sem nenhuma possibilidade de ressuscitação (LEITE e PRADO, 2019). A morte também pode ser declarada quando há extinção da atividade cerebral mesmo que ainda exista atividade de alguns de seus órgãos ou tecidos, os quais podem ser úteis para fins de transplante, enxerto ou cultura (MELÉNDEZ ESPINOZA, 2018).

É mister destacar que a morte era determinada, no passado, apenas por critérios cardiorrespiratórios, todavia com a avanço da tecnologia aliada a medicina, estes critérios mudaram. É possível sustentar as funções cardiorrespiratórias em pessoas com morte encefálica através de ventilação mecânica e cuidados intensivistas (RODRIGUES FILHO, 2015). Esses cuidados são ímpares quando se objetiva a doação de órgãos para transplante.

No Brasil, para diagnosticar a morte encefálica é preciso atender a Resolução 1.480/97 do Conselho Federal de Medicina que estabelece a necessidade de dois exames clínicos com intervalos mínimos definidos por faixa etária e a realização de exames complementares, tais como: angiografia cerebral, cintilografia radioisotópica, doppler transcraniano, monitorização da pressão intra-craniana, tomografia 
computadorizada com xenônio, tomografia por emissão de foton único, EEG, tomografia por emissão de pósitrons, extração cerebral de oxigênio e outros.

Infelizmente, nem todos os casos de óbitos são conhecidos, pois há casos onde o falecimento não ocorre na presença do médico. Além disso, há situações de óbitos suspeitos e cadáveres são encontrados sem se saber o momento do evento fatal. Para determinar os mecanismos e os aspectos forenses da morte surge a tanatologia forense. Ela também é conhecida como tanatologia médico-legal e se destina estudar a morte e o cadáver com suas repercussões no campo jurídico-social (FRANÇA, 2018).

É sabido que a morte é a consequência do processo natural de envelhecimento, de doenças, acidentes, suicídios ou crimes, logo nem sempre é fácil se ter exata precisão da morte. Todavia, com o advento da evolução tecnológica fica cada dia mais fácil diagnosticar o exato motivo da morte (LEITE e PRADO, 2019). Quando há morte suspeita ou violenta, cabe a tanatologia forense estabelecer a causa morte e todos os fenômenos médicos e legais relacionados a ela. E, no que tange a lei, cabe ao médico firmar declarar o óbito e sua(s) causa(s). Quando se investiga uma morte suspeita ou mesmo um crime, é imprescindível a perícia médica para se determinar a causa jurídica do óbito para continuar nas investigações.

Cabe a tanatologia forense investigar as circunstâncias envolvidas na morte, como alterações corporais que acompanham a morte e o período post mortem através de exame de necropsia, coleta de dados clínicos da vítima e exames complementares que poderão conduzir as causas e circunstâncias da morte. Para então, redigir uma conclusão que será encaminhada a autoridade competente (LEITE e PRADO, 2019).

Considerando, a importância da tanatologia forense para auxiliar a desvendar crimes, foi desenvolvido o presente estudo que teve como objetivo descrever os fenômenos da morte a partir dos conhecimentos oriundos da tanatologia. Ele consistiu em uma revisão descritiva cujas bases de dados foram: Scielo, RECAAP, PubMed e Web of Science. Os descritores utilizados foram: tanatologia, thanatology, tanatognose e foram considerados trabalhos escritos em português, espanhol ou inglês. 


\section{REVISÃO DE LITERATURA}

\subsection{MODALIDADES DE MORTE}

A palavra tanatologia tem origem na mitologia na qual Tânatos era a personificação do deus da morte. Como a tanatologia estuda a morte e o morto, faz-se necessário entender que existem diferentes tipos de morte, tais como: anatômica, histológica, aparente, relativa, intermediária e real (LUZ; DOMINGUES e NAVES, 2018; CROCE e CROCE JR., 2012).

A morte anatômica ocorre quando há a interrupção completa e definitiva das funções do organismo e sua relação como o meio ambiente. Já a morte histológica é decorrente da anterior. Ela é um processo de degradação lento das células e tecidos dos órgãos e sistemas.

A morte aparente é um estado que simula a morte por precária persistência da circulação e pode durar por horas, porém é possível a recuperação através de atendimento médico imediato e adequado. Já a morte relativa ocorre quando há parada cardiorrespiratória associada a cianose, ausência de pulsos e palidez marmórea, porém a pessoa pode ser ressuscitada com manobras terapêuticas.

A morte intermédia não é aceita de forma unânime, pois ela é relatada como uma experiência de quase morte, ou seja, os relatos dos sobreviventes são de percepção de desconexão do corpo com a alma. Ela sucede a morte relativa precede a morte absoluta. Por sua vez, a morte absoluta é a morte real, isto é, quando de forma irreversível há cessação das funções biológicas e se tem início os fenômenos cadavéricos.

Há ainda três classificações de morte que são de interesse jurídico, a saber: a morte natural, a violenta e a suspeita.

A morte natural é resultado da falência dos órgãos devido ao processo natural de envelhecimento ou devido às doenças. E nesse caso, se o óbito ocorrer sem assistência médica à declaração de óbito deverá ser fornecida pelo Serviço de 
Verificação de Óbitos (SVO), na sua ausência pelo médico do serviço público de saúde do local mais próximo onde ocorreu o evento ou na sua ausência, pelo médico local. Porém, se o óbito ocorrer com assistência médica, à declaração de óbito é fornecida pelo médico que assistia o paciente; ou em caso de regime hospitalar pelo médico assistente e, na sua ausência, por médico substituto pertencente à instituição; ou sob regime ambulatorial pelo médico designado pela instituição que prestava assistência, ou pelo SVO; ou sob regime domiciliar pelo médico que pertence ao programa ao qual o paciente estava cadastrado; ou pelo SVO, se o médico não poder estabelecer a relação do óbito com o quadro clínico respectivo ao acompanhamento do paciente (OLIVEIRA ANDRADE e BARROS GARÇÃO, 2005).

A morte violenta é resultado de homicídio, suicídio ou acidente. E a morte suspeita é aquela que há suspeita de a morte não ter sido natural, ou seja, poderia ser uma morte violenta, logo neste caso é necessária uma cuidadosa investigação médica-legal e criminal. Nesses casos, quem deve fornecer a declaração de óbito é o perito legista do Instituto Médico Legal, ou seja, obrigatoriamente é emitida pelo serviço médicolegal.

\subsection{TANATOGNOSE}

Etimologicamente a tanatognose significa diagnóstico da morte, ou seja, ela é a parte da tanatologia que busca estabelecer o diagnóstico do óbito através da análise dos fenômenos cadavéricos abióticos e transformativos (SOUZA et al, 2018). É sabido que antes do aparecimento dos fenômenos transformativos não existe um sinal característico de morte e cabe ao perito a responsabilidade de analisar os fenômenos cadavéricos (CROCE e CROCE JR., 2012).

Os fenômenos cadavéricos abióticos (ou avitais) podem ser divididos em imediatos e consecutivos. Os fenômenos abióticos imediatos não confirmam o óbito, pois há casos nos quais eles podem ser revertidos através de manobras terapêuticas emergenciais. Por sua vez, os consecutivos caracterizam o óbito, mas a presença de alguns sinais isoladamente não tem valor absoluto. 
Os sinais abióticos imediatos que insinuam a morte, são: parada cardiovascular, parada respiratória, perda da consciência, atonia muscular com imobilidade, perda da sensibilidade, relaxamento dos esfíncteres, fáceis hipocrática, pálpebras parcialmente cerradas, midríase (LUZ; DOMINGUES e NAVES, 2018; SILVEIRA, 2015).

Já os sinais abióticos consecutivos surgem paulatinamente após o óbito e são eles: desidratação, resfriamento gradual do corpo, rigidez e espasmo, manchas cutâneas hipostáticas e livores cadavéricos (LUZ; DOMINGUES e NAVES, 2018; CROCE e CROCE JR., 2012). É mister ressaltar que o local e as condições do óbito influenciam de forma significativa no desenvolvimento dos fenômenos cadavéricos, por isso é preciso uma análise muito criteriosa para prevenir erros de interpretações.

É sabido que a desidratação no cadáver representa uma perda passiva de fluído corporal e, fundamentalmente, sofre influência da temperatura do ambiente, da umidade de ar e das correntes de ar e condições pretéritas do cadáver. Ela pode facilitar a formação de mancha negra da esclerótica (livor sclerotinae nigrecens ou sinal de Sommer e Larcher), turvação da córnea, tela viscosa no olho (sinal de StenonLouis) e diminuição da tensão do olho, além de deixar as mucosas com coloração parda e consistência dura e diminuir o peso do corpo (SOUZA et al, 2018; CROCE e CROCE JR., 2012).

O resfriamento (algor mortis) decorre da ausência da atividade metabólica, logo um cadáver não gera e nem mantém calor e a tendência é que a temperatura se iguale a temperatura ambiente. $\mathrm{O}$ cadáver tende a perder $1^{\circ} \mathrm{C}$ de temperatura por hora, mas é claro há fatores intervenientes, tais como: peso do cadáver, graus de adipocidade, condições ambientais, doenças infecciosas, os esforços físicos no momento precedente à morte, dentre outros. $O$ equilíbrio térmico entre o cadáver e o meio ambiente ocorre em torno de 24 a 26 horas nos adultos e 20 horas nas crianças (FRANÇA, 2018; CROCE e CROCE JR., 2012).

A rigidez cadavérica (rigor mortis) consiste num tipo específico de contração muscular do cadáver que surge dentro de uma a três horas após a morte (Figura 1). Essa contração é resultado da perda do ATP total imprescindível para afastamento de 
pontes cruzadas dos filamentos de actina e misosina no processo de relaxamento. $\mathrm{O}$ músculo permanece rígido até que proteínas musculares sejam desintegradas, o que em regra ocorre por autólise com enzimas liberadas dos lisossomos (POPOSKA et al., 2013). E segundo a Lei de Nysten-Sommer, se o cadáver estiver em posição supina, à rigidez tem início da face, nuca e depois no tórax, membros superiores, abdômen e membros inferiores e desaparece na mesma sequência. Ela é concluída entre 12 a 15 horas e desaparece entre 20 a 24 horas (MELÉNDEZ ESPINOZA, 2018; SOUZA et al, 2018; CROCE e CROCE JR., 2012). No entanto, dependendo do cadáver o desaparecimento da rigidez pode começar 36 horas após a morte, ou em outros casos após dois ou três dias (LEITE e PRADO, 2019).

O rigor mortis se desenvolve rapidamente se o corpo estiver acidótico no momento da morte, pois ele está relacionado a uma diminuição de pH nos miócitos (PRESNELL e DENTON, 2015).

Figura 1: Rigor mortis persistente com o braço direito desafiando a gravidade. O corpo deveria estar em outra posição por várias horas após a morte antes de ser colocado em posição supina.

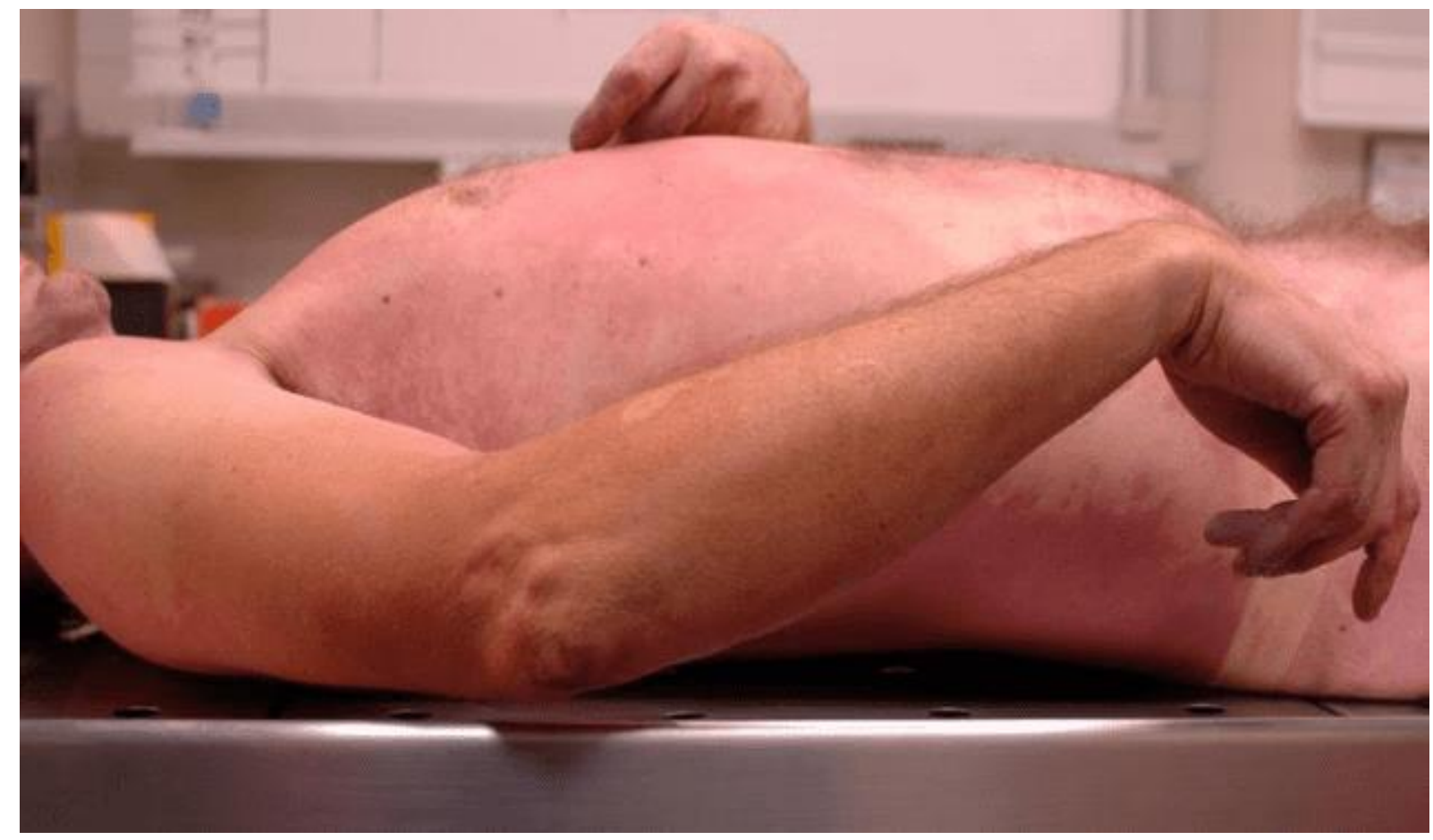

Fonte: PRESNELL e DENTON, 2015 
O espasmo cadavérico é um tipo de rigidez cadavérica instantânea que ocorre logo após a morte e precede a rigidez e pode ser confundido com ela. Ele pode aparecer em vítima de violência e morte súbita e o cadáver mantém a posição do momento do óbito e é também conceituado como rigidez cadavérica cataléptica ou estuária (LEITE e PRADO, 2019).

Outro fenômeno que o cadáver desenvolve é a mancha cutânea hipostática (livor mortis) se caracteriza pela presença de mancha de estase sanguínea na pele do cadáver no nível das partes que estão em declínio (Figuras 2 e 3). E internamente, formam a hipóstase visceral. Essas manchas surgem cerca de três horas após a morte e podem mudar de posição nas primeiras 12 horas, nas 12 horas seguintes novas manchas podem aparecer e não se formam outras após 24 horas, apenas começam a desaparecer as existentes (MELÉNDEZ ESPINOZA, 2018).

O livor de hipóstase (livor mortis) e a lividez são dois fenômenos que ocorrem concomitantemente, pois com o óbito a circulação é cessada. (SOUZA et al, 2018). Com a morte, a pressão intravascular cai à zero, logo o sangue sofre a ação da gravidade e migra para as partes mais baixas do corpo e, por sua vez, as regiões mais elevadas irão perder o sangue e surgindo pequenas manchas isoladas, com tonalidade cinza-arroxeada. Depois, essas manchas tendem aumentar de tamanho e espalhar pelas áreas com mais declives do cadáver. Nas áreas que estão submetidas à compressão não há formação de livor. No entanto, se o cadáver for de uma pessoa com anemia severa ou que tenha perdido muito sangue, o livor será discreto ou imperceptível (GONÇALVES, 2019). Há situações em que o rigor mortis ou livor mortis podem gerar padrões inconsistentes devido ao efeito da gravidade no local. $E$ isso pode ser indício de que o corpo foi movido na cena do crime (PRESNELL e DENTON, 2015). 
Figura 2. Livor mortis em uma posição anterior. A área de empalidecimento no tórax e no abdômen resultou do falecido deitado em cima do braço esquerdo e mão direita.

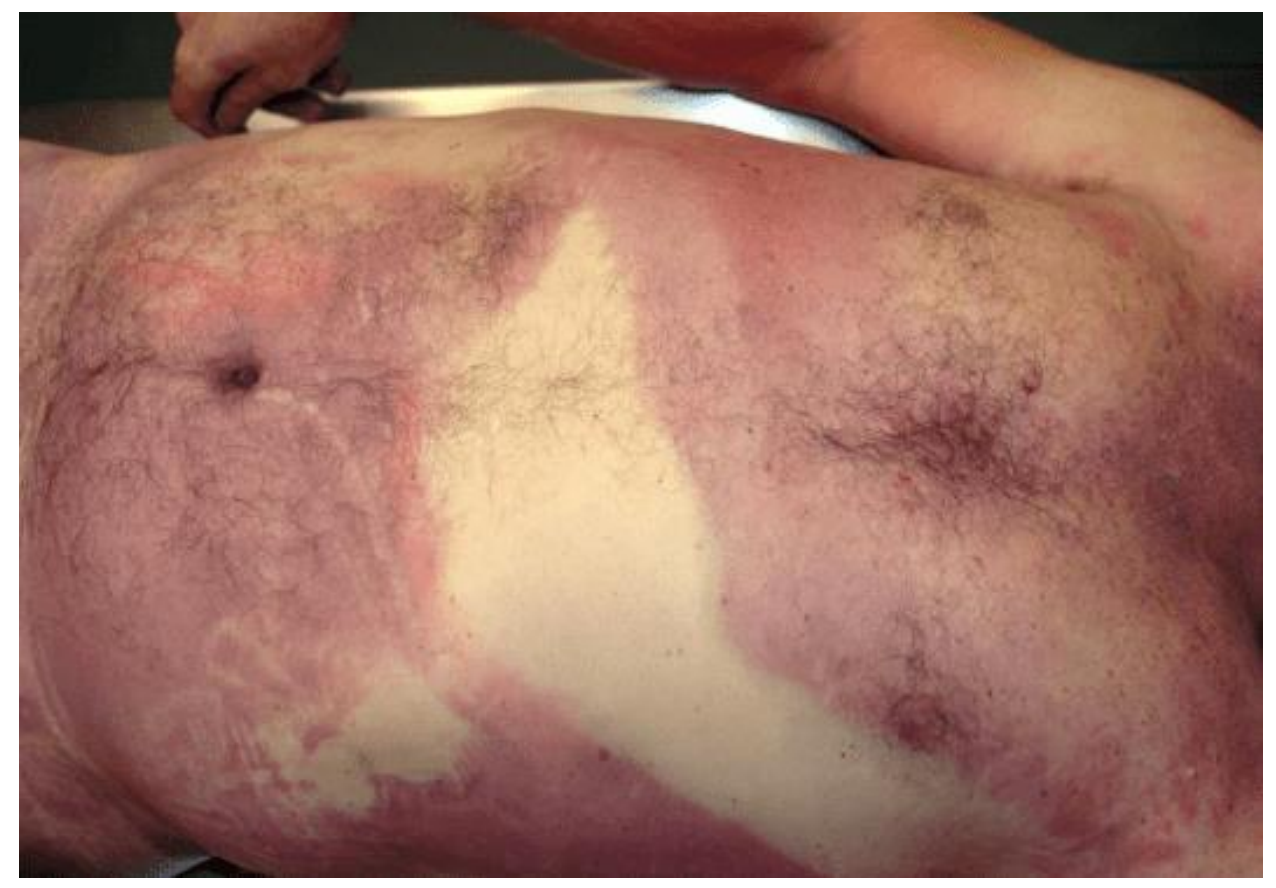

Fonte: PRESNELL e DENTON, 2015

Figura 3: Livor mortis nos aspectos posteriores do corpo.

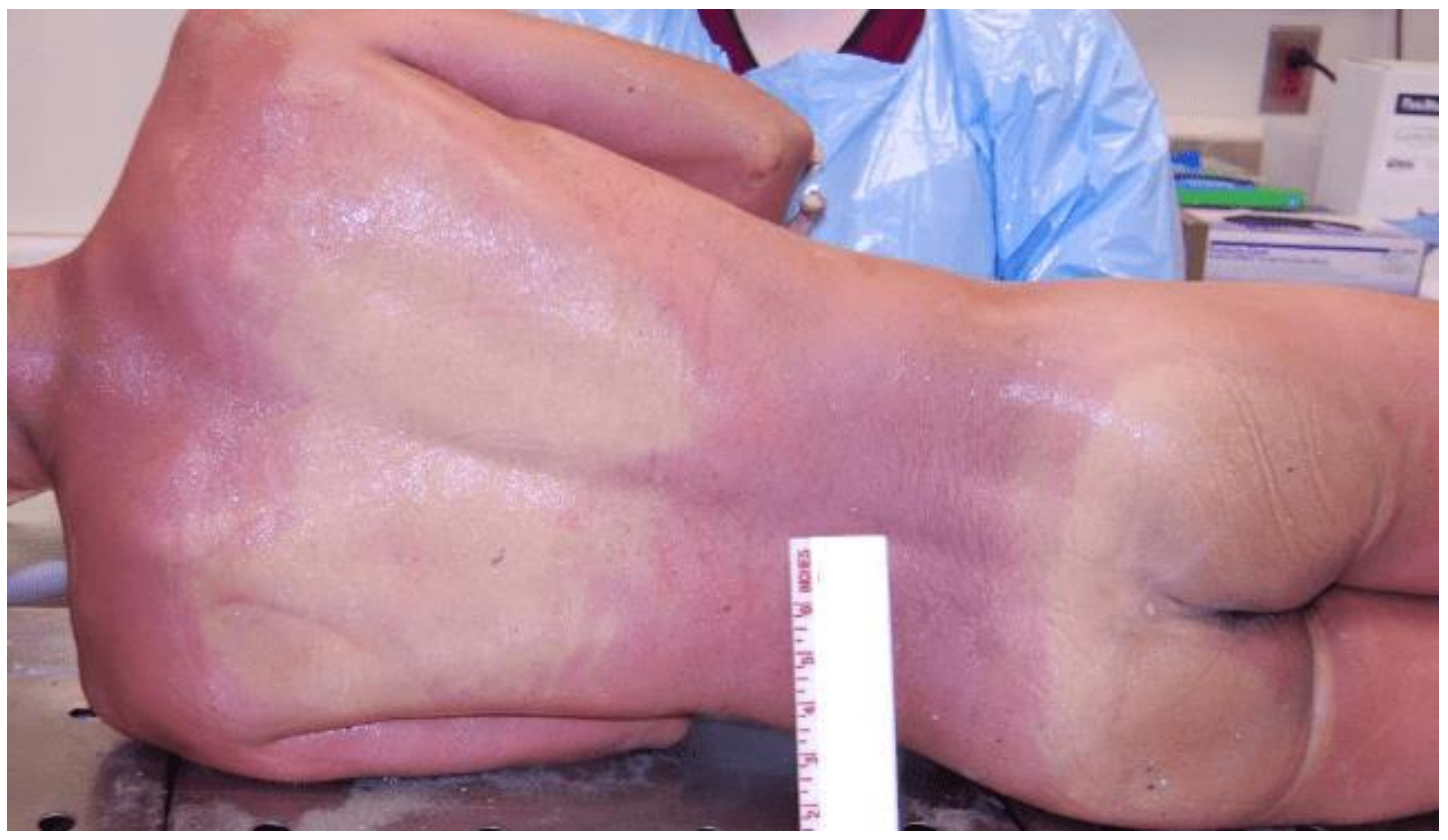

Fonte: PRESNELL e DENTON, 2015

RC: 43392

Disponível em: https://www.nucleodoconhecimento.com.br/saude/tanatologia 
Há ainda os fenômenos transformativos que podem ser de dois tipos: destrutivos e conservadores. Os sinais destrutivos são: a autólise, putrefação e maceração; e os conservadores são: mumificação, saponificação, calcificação e corificação (FRANÇA, 2018).

A autólise ocorre quando a circulação sanguínea é interrompida e consequentemente não há trocas nutritivas e de oxigenação entre as células e circulação. Esse fato gera o aumento da acidez e decomposição intra e extracelulares. Por sua vez, a putrefação tem início após a autólise e envolve a ação microbiana aeróbia e anaeróbia. É sabido que o corpo já possui bactérias que fazem parte da flora natural, principalmente, a flora intestinal, por isso é comum que a putrefação se inicie no intestino e como consequência surge um sinal de "mancha verde abdominal" (Figura 4). Essa mancha representa a evidência da decomposição dos tecidos justamente na região onde há maior abundância de bactérias, ou seja, nas alças intestinais (SILVEIRA, 2015).

Figura 4: As alterações decompositivas iniciais são manifestadas pela descoloração verde sobre o abdômen.

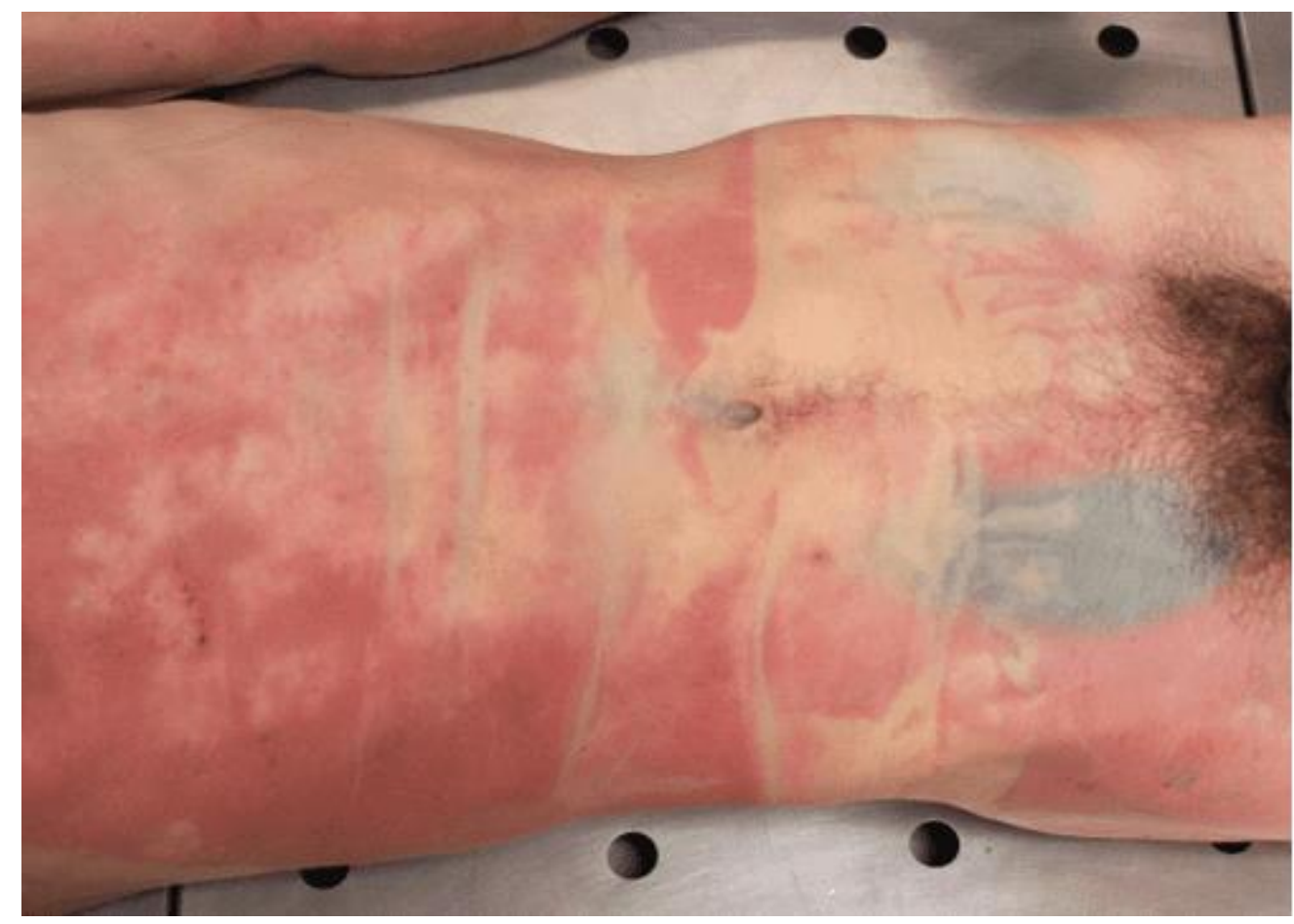

Fonte: PRESNELL e DENTON, 2015 
A putrefação é dividida em quatro períodos, o primeiro é denominado período de coloração. Nesse período surge uma mancha verde na parede abdominal da fossa ilíaca direita devido à combinação entre hidrogênio sulfurado com a hemoglobina formando a sulfometemoglobina. Essa mancha surge entre 18 e 24 horas após a morte e dura cerca de uma semana e será distribuída todo o tronco, cabeça e membros. O segundo é o período gasoso que dura em média duas semanas e ocorre porque o gás sulfídrico oriundo da putrefação migra para superfície do corpo. O cadáver assume uma postura de boxeador, com face, tronco, pênis e escroto edemaciados, presença de circulação póstuma de Brouardel, útero grávido produz o parto de putrefação.

O terceiro período é o coliquativo que se inicia na primeira semana após a morte e pode se estender por até três anos (Figura 5). Nele há dissolução pútrida das partes moles e dos ossos graças à ação de bactérias e da fauna necrófaga.

Figura 5: Decomposição é um processo de autólise e putrefação.

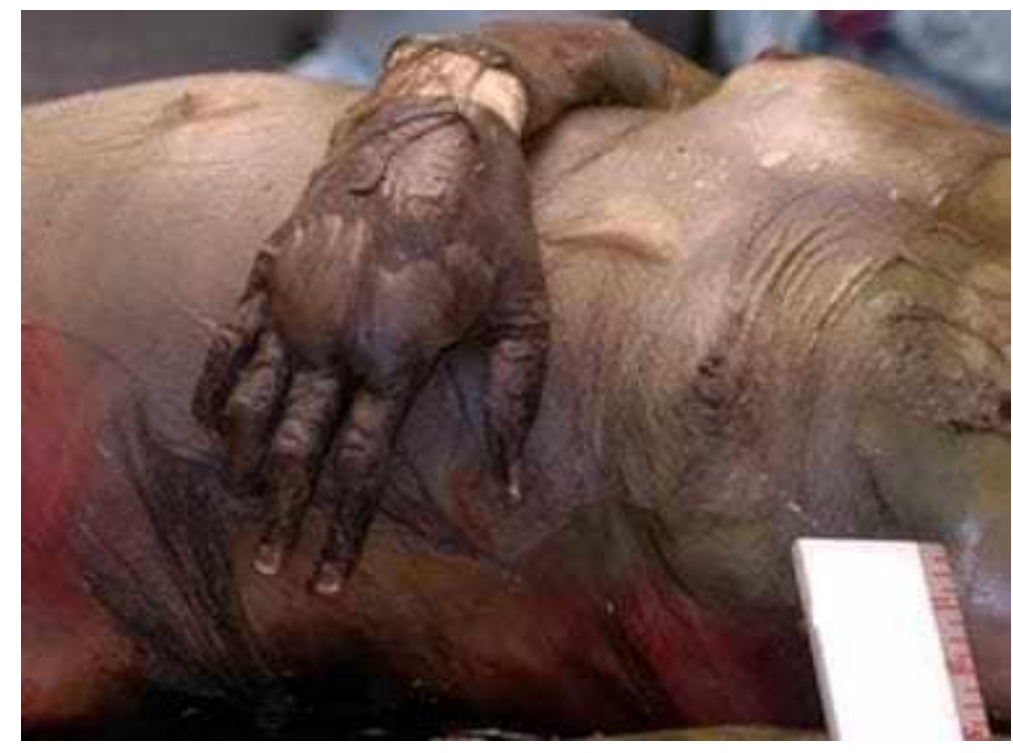

Fonte: PRESNELL e DENTON, 2015

E o último período é a esqueletização, no qual há exposição de ossos e dentes (Figura 6). Sua concretização pode durar mais de três anos, porém com o tempo mesmo 
essas estruturas rígidas se tornam mais leves, frágeis e quebradiças (SOUZA et al, 2018; FRANÇA, 2018; CROCE e CROCE JR., 2012).

Figura 6: Este esqueleto é o de um homem adulto.

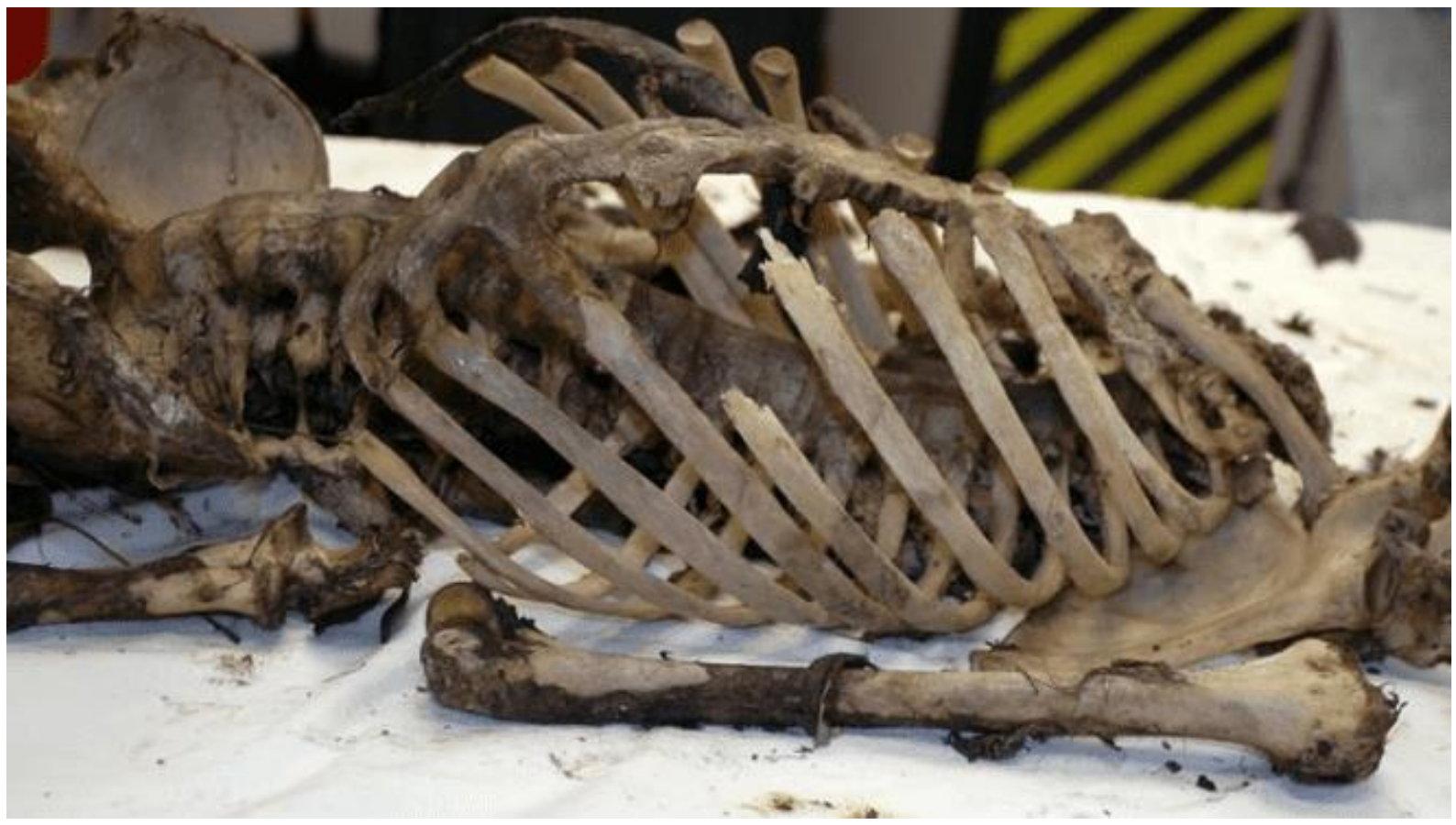

Fonte: PRESNELL e DENTON, 2015

Ainda é possível a existência da maceração, a qual ocorrer quando há cadáver fetal a partir do 5.ำ mês de gestação no útero materno ou em casos de afogamento. A maceração tem como característica o descolamento da pele do corpo como se fosse um tecido à parte (SOUZA et al, 2018).

Já os fenômenos conservativos atrasam a decomposição do cadáver e dependem das condições ambientais e do próprio corpo, e são eles: saponificação, mumificação, calcificação, corificação, congelação e fossilização (LUZ; DOMINGUES e NAVES, 2018).

É bom descartar que determinar a causa da morte, o período no qual ela se sucedeu e se houve tortura são fatores primordiais em casos de morte suspeita e morte violenta. Esses fatos podem agravar a pena do acusado ou por outro lado gerar elementos atenuantes. Cabe ao perito emitir laudos periciais que orientam as 
autoridades policiais, advogados, juristas sobre a realidade dos fatos de interesse da Justiça.

\section{CONSIDERAÇÕES FINAIS}

A morte sempre envolve conflitos emocionais e religiosos, porém para a tanatologia o que interessa é a cientificidade da morte. Determinar se a morte foi natural, violenta ou suspeita pode fazer muita diferença para a família e trazer fatos para que a Justiça seja concretizada.

Para se estabelecer o diagnóstico da morte é preciso que o médico acompanhe o paciente durante o percusso da doença ou possa realizar um exame de necropsia quando a causa não possa ser previamente determinada. O diagnóstico deve ser elaborado por um perito que deverá observar determinados fenômenos cadavéricos.

Conhecer os fenômenos cadavéricos abióticos e transformativos é primordial para se determinar o diagnóstico de certeza da morte, quando e como ela ocorreu.

Os fenômenos imediatos permitem a análise dos sinais que gerem a morte, já os fenômenos consecutivos indicam de forma segura a morte, enquanto os fenômenos transformativos definem as alterações que o corpo sofre durante a decomposição.

\section{REFERÊNCIAS}

CONSELHO FEDERAL DE MEDICINA. Resolução CFM № 1.480, de 8 de agosto de 1997. Critérios de morte encefálica. Diário Oficial da União. 21 ago 1997; seção 1:2278. Disponível em: http://www.portalmedico.org.br/resolucoes/cfm/1997/1480_1997.htm Acesso em: 19 dez. 2019.

CROCE, Delton e CROCE JR., Delton. Manual de Medicina Legal. São Paulo: Saraiva, 2012. 
FRANÇA, Genival Veloso de. Fundamentos de Medicina Legal. 3. ed. Rio de Janeiro: Guanabara Koogan, 2018.

GONÇALVES, Nilo Jorge Rodrigues. Livor mortis na prática médico-legal. Persp Med Legal Pericias Med. São Paulo, n.8, fev, 2019. Disponível em: http://perspectivas.med.br/2019/02/livor-mortis-na-pratica-medico-legal/ 22 dez. 2019.

LEITE, Gabriela Alonge Almeida; PRADO, Florestan Rodrigo do. Sinais abióticos: putrefação, autólise, maceração. ETIC - Encontro de Iniciação Científica 2019. v.15, n. 15. Toledo Prudente Centro Universitário, São Paulo, Parque Furquim, 2019. ISSN 21-76-8498. Disponível

em: http://intertemas.toledoprudente.edu.br/index.php/ETIC/article/view/7892/67648627 Acesso em: 19 dez 2019.

LUZ, Bernardo Araujo da; DOMINGUES, Helane Cristina Pinheiro; NAVES, Carlos Luiz de Lima. Medicina Forense. Londrina: Editora e Distribuidora Educacional S.A., 2018. 200 p.

MELÉNDEZ ESPINOZA, Juan Jose. Nivel de conocimiento sobre las medidas de bioseguridad en tanatologia forense de los profesionales del Ministerio Público de Ucayali. Monografia (Licenciado en Enfermería), Universidad Nacional de Ucayali, Facultad de Ciencias de la Salud, Pucallpa, Perú, 2018, 89 p.

OLIVEIRA ANDRADE, Edson; BARROS GARÇÃO, Lívia. Resolução CFM ํำ1.779/05 Revista Bioética, v. 13, n. 1, 2005, pp. 147-149 Conselho Federal de Medicina. Brasília, Brasil.

OLIVEIRA, Renato Alves de. O instante da morte. A hipótese da decisão final. Revista Eclesiástica Brasileira, [S.I.], v. 75, n. 300, p. 855-888, ago. 2015. ISSN 2595-5977. Disponível em: <http://revistaeclesiasticabrasileira.itf.edu.br/reb/article/view/267>. Acesso em: 19 dez. 2019. doi: http://dx.doi.org/10.29386/reb.v75i300.267.

POPOSKA, V.; GUTEVSKA, A.; STANKOV, A.; PAVLOVSKI, G.; JAKOVSKI, Z. \& JANESKA, B. Estimation of Time Since Death by using Algorithm in Early Postmortem 
Period. Global Journal of Medical research Interdsciplinary. v.13, n.3, pp. 16-26, 2013. Online ISSN: 2249-4618. Disponível em: https://pdfs.semanticscholar.org/33a5/b4066d3efc688dc0ffefb3e4f9f0b72aeee9.pdf? _ga=2.195754859.693363788.1577023617-619074019.1577023617 Acesso em: 22 dez. 2019.

PRESNELL, S. Erin; DENTON, J. Scott. Postmortem Changes. Medscape. Oct 13th, 2015. Disponível em: https://emedicine.medscape.com/article/1680032-overview Acesso em: 22 dez. 2019.

SILVEIRA, Paulo Roberto. Fundamentos da Medicina Legal. $2^{\underline{a}}$ ed. Rio de Janeiro: Lumen Juris, 2015. 638 p.

SOUZA, Paula Helena dos Santos e; et al. A tanatognose por observação dos fenômenos cadavéricos. Revista Científica Multidisciplinar Núcleo do Conhecimento. a.3, e.7, v. 6, pp. 28-42, jul. 2018. ISSN: 2448-0959.

Enviado: Dezembro, 2019.

Aprovado: Janeiro, 2020. 